\title{
PERBEDAAN KONSUMSI YOGURT MENGANDUNG POLYDEXTROSE DENGAN YOGURT TERHADAP KEJADIAN KONSTIPASI PADA IBU HAMIL
}

\author{
Indri Lovely Auria ${ }^{1}$, Neneng Siti Lathifah², Dainty Maternity ${ }^{3}$, Suharman $^{4}$
Email : aindrilovely@gmail.com
2Dosen Program Studi DIV Kebidanan Fakultas Kedokteran Universitas Malahayati Bandar Lampung
Email : nenengmalahayati@gmail.com
${ }^{3}$ Dosen Program Studi DIV Kebidanan Fakultas Kedokteran Universitas Malahayati Bandar Lampung
Email : denty.mf@gmail.com
${ }^{4}$ Dosen Program Studi DIV Kebidanan Fakultas Kedokteran Universitas Malahayati Bandar Lampung
Email : hermanari62@gmail.com \\ 1'Mahasiswa Program Studi DIV Kebidanan Fakultas Kedokteran Universitas Malahayati Bandar Lampung
}

\begin{abstract}
Backgroundln Indonesia the case of constipation suffered by pregnant women is around 4-30\%, while the constipation suffered by people over old age is around $2-25 \%$ at the age of 60 years and over. The incidence of constipation increases with age and the use of iron supplements. The incidence of constipation in pregnant women in Indonesia reaches 15-20\%.

The purpose of this study is to know the effect of yogurt consumption on the incidence of pregnant women at BPM Fitri Hayati S.ST Bandar Lampung in 2019.

Methods This type of quantitative research, research design approach to quasi experimental design with pretest-posttest with control group design. the sample of all pregnant women was 30 people. 15 people as an experimental group and 15 others as a control group with a purposive sampling technique. Data analysis with independent T-test.

The results of this study indicate the average frequency of chapters after consumption of yogurt containing polydextrose in pregnant women who have contipation at BPM Fitri Hayati S.ST Bandar Lampung in 2019 is 23.60 and the average frequency of chapters before yogurt consumption in pregnant women who experience contipation in BPM Fitri Hayati S. ST Bandar Lampung in 2019 is 19.20.

Conclusion there is an effect of giving yogurt consumption on the incidence of constipation in pregnant women at BPM Fitri Hayati S. ST Bandar Lampung in 2019. The results of the t test obtained $p$ value $0,000<\alpha(0$, $05)$.

Suggestion Can be used as a non-pharmacological method to overcome the contipation that occurs in pregnant women while consuming Polydextrose Yogurt which is very effective for curing constipation.

Keywords : Consumption Yogurt Polydextrose and Yogurt, Contipation

\section{ABSTRAK}

Latar Belakang Di Indonesia kasus konstipasi yang diderita oleh wanita hamil sekitar 4-30\%, sedangkan konstipasi yang diderita masyarakat di atas usia lanjut sekitar 2-25\% pada usia 60 tahun ke atas. Insiden konstipasi tersebut meningkat seiring dengan pertambahan umur dan penggunaan suplemen zat besi.Insiden konstipasi pada ibu hamil di Indonesia mencapai $15-20 \%$

Tujuan dari penelitian ini adalah diketahui pengaruh konsumsi yogurt terhadap kejadian ibu hamil di BPM Fitri Hayati S.ST Bandar Lampung Tahun 2019.

Metode Jenis penelitian kuantitatif, rancangan penelitian pendekatan quasi eksperimental deain dengan rancangan pretest-posttest with control group. sampel seluruh ibu hamil sebanyak 30 orang. 15 orang sebagai kelompok eksperimen dan 15 orang lainya sebagai kelompok control dengan teknik sampling purposive sampling. Analisa data dengan uji T-test independent.

Hasil penelitian ini menunjukkan rata-rata frekuensi bab sesudah konsumsi yogurt yang mengandung polydextrose pada ibu hamil yang mengalami kontipasi di BPM Fitri Hayati S.ST Bandar Lampung Tahun 2019 yaitu 23.60 dan rata-rata frekuensi bab sebelum konsumsi yogurt pada ibu hamil yang mengalami kontipasi di BPM Fitri Hayati S.ST Bandar Lampung Tahun 2019 yaitu 19.20.
\end{abstract}


Kesimpulan ada pengaruh pemberian konsumsi yogurt terhadap kejadian konstipasi pada ibu hamil di BPM Fitri Hayati S.ST Bandar Lampung Tahun 2019. Hasil uji t didapat p value $0,000<a(0,05)$.

Saran Dapat dijadikan sebagai metode nonfarmakologi untuk mengatasi kontipasi yang terjadi pada ibu hamil sengan mengkonsumsi Yogurt Polydextrose yang sangat efektif untuk menyembuhkan sembelit.

Kata Kunci : Konsumsi Yogurt Polydextrose dan Yogurt,Kontipasi

\section{PENDAHULUAN}

Konstipasi sering dialami oleh ibu hamil.Perubahan hormone akibat kehamilan atau pola hidup dapat memicu timbulnya ganguan ini.Awalnya sambelit hanya menyebabkan ketidaknyamanan selama buang air besar dan perut menjadi sakit atau kembung. Tetapi jika ini berlangsung lama akan menggangu metabolisme tubuh dan menimbulkan gangguan tubuh yang lainnya. (Jika konstipasi dibiarkan berlangsung terus menerus dapat menyebabkan timbulnya wasir.(Widyasari,2017) akibat terjadinya sembelit, ibu hamil akan menjadi terlalu sering mengejan ketika buang air besar, oto-otot pada pembuluh darah di anus melemah, akibatnya keduanya dapat mempertinggi kemungkinan terjadinya wasir pada ibu hamil. Oleh karena itu, sembelit pada ibu hamil harus segera diatasi. (Dwisulistyowati,2016)

Menurut Probosuseno, di Indonesia kasus konstipasi yang diderita oleh wanita hamil sekitar 4$30 \%$, sedangkan konstipasi yang diderita (Mualimah,2019). Masyarakat di atas usia lanjut sekitar 2-25\% pada usia 60 tahun ke atas. Wanita hamil lebih sering mengeluh kesulitan $B A B$ dibanding wanita usia lanjut dengan perbandingan 3 : 1 hingga 2 : 1 . Insiden konstipasi tersebut meningkat seiring dengan pertambahan umur dan penggunaan suplemen zat besi.Insiden konstipasi pada ibu hamil di Indonesia mencapai 15-20 $\%$.(Riza,N,2017)

BPM Fitri Hayati S.ST adalah salah satu Bpm di Bandar Lampungyang terletak di JIn.Imam bonjol, Bandar Lampung Cakupan K4 di BPM ini sudah mencapai $80 \%$. Berdasarkan survey awal peneliti pada Bulan Mei pada tanggal 1-16 Mei yang dilakukan di BPM Fitri Hayati S.ST, diketahui bahwa dari 34 orang ibu hamil yang memeriksakan kandungannya 11 orang diantaranya mengeluh susah buang air besar atau konstipasi dengan ketidaknyamanan seperti feses dan perut kembung sehingga meminta bidan untuk mengatasi masalahnya.

\section{METODOLOGI PENELITIAN}

Penelitian ini dilaksanankan diwilayah kerja BPM Fitri Hayati S.ST Bandar lampung. Waktu penelitian ini dilaksanakan pada tanggal 9 - 23 Juni 2019 . Dalam penelitian ini menggunkaan Rancangan penelitian yang digunakan dalam penelitian ini adalah Quasi Experimen Design dengan rancangan Two Group Pre-Post Test Design.(Notoatmojo,2014) Ciri dari desain penelitian ini memberikan intervensi pada respenden yang akan dilakukan tindakan perlakuan dan membandingkan sebelum dan sesudah dilakukan intervensi. Penelitian ini memberikan intervensi kepada kelompok yang akan diberikan yogurt yang mengandung polydextrose. sampel pada penelitian ini adalah seluruh ibu hamil pada trimester kedua dan trimester ketiga yang berjumlah 30 responden selama 2 minggu dan teknik yang digunakan dalam penelitian ini adalah Accidental sampling.

\section{HASIL PENELITIAN Uji Normalitas}

Tabel 1 Hasil Uji Normalitas Test of Normality

\begin{tabular}{ll}
\hline \multirow{2}{*}{ Kelompok } & Shapiro Wilk \\
\cline { 2 - 2 } & Sig. \\
\hline Pretest Yogurt Polydextrose & 0.052 \\
Posttest Yogurt Polydextrose & 0.081 \\
Pretest Yogurt & 0.056 \\
Posttest Yogurt & 0.445 \\
\hline
\end{tabular}

Table diatas menunjukkan bahwa uji normalitas menggunakan Kolmogorov-Smirnov pada variable ibu hamil yang mengalami konstipasi sebelum perlakuan pada Kelompok Eksperimen 0.052, setelah perlakuan pada Kelompok Eksperimen 0.081, ibu hamil yang mengalamii konstipasi sebelum perlakuan pada Kelompok Kontrol 0.056, setelah perlakuan pada Kelompok Kontrol 0.445 , karena $P>0.05$ maka dapat disimpulkan semua data berarti data berdistribusi normal. 
Analisa Univariat

Kelompok Yogurt Polydextrose

Tabel 2 Rata - Rata ibu yang menglami konstipasi sebelum dan sesudah mengkomsumsi Yogurt Polydextrose pada ibu hamil di BPM Fitri Hayati S.ST

\begin{tabular}{lccccc}
\hline \multicolumn{1}{c}{ Variabel } & N & Mean & SD & Min & Max \\
\hline $\begin{array}{l}\text { Rata-Rata ibu yang mengalami konstipasi } \\
\text { sebelum komsumsi Yogurt Polydextrose }\end{array}$ & 15 & 2.3333 & 1.04564 & 1.00 & 4.00 \\
$\begin{array}{l}\text { Rata-Rata ibu yang mengalami konstipasi } \\
\text { sesudah komsumsi Yogurt Polydextrose }\end{array}$ & 15 & 23.6000 & 2.06328 & 20.00 & 26.00 \\
\hline
\end{tabular}

Berdasarkan tabel 2 diatas diketahui bahwa 15 responden penelitian, diperoleh hasil nilai mean atau nilai rata - rata ibu hamil yang mengalami konstipasi sebelum konsumsi Yogurt Polydextrose adalah sebesar 2.3333, standar deviasi sebesar 1.04567 , hasil rata -rata terendah atau hasil minimal yaitu 1.00 dan hasil jumlah tertinggi atau hasil maximal sebesar 4.00. Sedangkan nilai rata - rata ibu hamil yang mengalami konstipasi sesudah konsumsi Yogurt Polydextrose adalah sebesar 23.6000, standar deviasi sebesar 2.06328 , hasil rata -rata terendah atau hasil minimal yaitu 20.00 dan hasil jumlah tertinggi atau hasil maximal sebesar 26.00
Kelompok Yogurt

Berdasarkan tabel 3 diatas diketahui bahwa 15 responden penelitian, diperoleh hasil nilai mean atau nilai rata - rata ibu hamil yang mengalami konstipasi sebelum Konsumsi Yogurt adalah sebesar 2.2667, dengan nilai, standar deviasi sebesar 1.03280 , hasil rata -rata terendah atau hasil minimal yaitu 1.00 dan hasil jumlah tertinggi atau hasil maximal sebesar 4.00. Sedangkan nilai rata - rata ibu hamil yang mengalami konstipasi sesudah Konsumsi Yogurt adalah sebesar 19.2000, standar deviasi sebesar 1.47358, hasil rata -rata terendah atau hasil minimal yaitu 16.00 dan hasil jumlah tertinggi atau hasil maximal sebesar 22.00 .

Tabel 3 Rata - Rata ibu yang menglami konstipasi sebelum dan sesudah mengkomsumsi yogurt pada ibu hamil di BPM Fitri Hayati S.ST

\begin{tabular}{lccccc}
\hline \multicolumn{1}{c}{ Variabel } & N & Mean & SD & Min & Max \\
\hline $\begin{array}{l}\text { Rata-Rata ibu yang mengalami konstipasi } \\
\text { sebelum komsumsi yogurt }\end{array}$ & 15 & 2.2667 & 1.03280 & 1.00 & 4.00 \\
\hline $\begin{array}{l}\text { Rata-Rata ibu yang mengalami konstipasi } \\
\text { sesudah komsumsi yogurt }\end{array}$ & 15 & 19.2000 & 1.47358 & 16.00 & 22.00 \\
\hline
\end{tabular}

Analisa Univariat

Tabel 4 Hasil Konsumsi Yogurt Polydextrose dan Yogurt Terhadap Kejadian Konstipasi Pada lbu Hamil di BPM Fitri Hayati S.ST Bandar Lampung Tahun 2019

\begin{tabular}{lcccccccc}
\hline \multicolumn{1}{c}{ Variabel } & $N$ & Mean & T & $\begin{array}{c}\text { Std. } \\
\text { Deviation }\end{array}$ & $\begin{array}{c}\text { S. } \\
\text { Erorr } \\
\text { Mean }\end{array}$ & P-value & \multicolumn{2}{c}{$\begin{array}{c}95 \% \text { confidence interval } \\
\text { of the difference }\end{array}$} \\
\hline Posttets Yogurt & & & & & & & & \\
Lower & Upper \\
Polydextrose & 15 & 21.667 & 6.046 & 2.01660 & .52068 & 0.000 & 2.86525 & 5.80142 \\
Posttest Yogurt & 15 & 16.9333 & 6.046 & 1.90738 & .49248 & & 2.86505 & 5.80162 \\
\hline
\end{tabular}

Berdasarkan tabel 4 diatas didapatkan hasil rata-rata kenaikan ibu hamil yang sudah tidak mengalami konstipasi pada kelompok Yogurt Polydextrose sebesar 21.2667 dan rata rata kenaikan ibu hamil yang sudah tidak mengalami konstipasi pada kelompok Yogurt sebesar 16.9336. Uji t independent didapat $p$ value $0,000, a(0,05)$ artinya $\mathrm{HO}$ ditolak dan $\mathrm{Ha}$ diterima, dan didapatkan bahwa mean yogurt menggandung polydextrose lebih besar dari pada yogurt tidak menggandung polydextrose yang berarti ada perbedaan konsumsi yogurt menggandung polydextrose dangan yogurt terhadap kejadian konstipasi pada ibu hamil Di BPM Fitri Hayati S.ST bandar Lampung Tahun 2019 dan 
berdasarkan tabel diatas disimpulan bahwa mengkonsumsi yogurt yang menggandung polydextrose lebih efektf dibandingkan yogurt yang tidak menggandung polydextrose terhadap kejadian konstipasi pada ibu hamil.(Aziza,2017)

\section{PEMBAHASAN}

Berdasarkan hasil penelitian dapat diketahui bahwa 15 responden penelitian, diperoleh hasil nilai mean atau nilai rata - rata ibu hamil yang mengalami konstipasi sebelum konsumsi Yogurt Polydextrose adalah sebesar 2.3333, standar deviasi sebesar 1.04567 , hasil rata -rata terendah atau hasil minimal yaitu 1.00 dan hasil jumlah tertinggi atau hasil maximal sebesar 4.00. Sedangkan nilai rata - rata ibu hamil yang mengalami konstipasi sesudah konsumsi Yogurt Polydextrose adalah sebesar 23.6000 , standar deviasi sebesar 2.06328, hasil rata -rata terendah atau hasil minimal yaitu 20.00 dan hasil jumlah tertinggi atau hasil maximal sebesar 26.00.

$\mathrm{Hal}$ ini sesuai dengan teori bahwa mengkonsumsi yogurt pada ibu hamil yang mengandung polydextrose lebih efektif dari pada yogurt yang tidak mengandung polydextrose pada ibu hamil yang mengalami kontipasi dan dapat disimpulkan mengkonsumsi yogurt menggandung polydextrose adalah adalah pilihan terbaik. Karna yogurt yang mengandung polydextrose mempunyai komponen aktif secara biologis. Pertama,mengkonsumsi yogurt dapat mengurangi ph diusus, penurunan $\mathrm{pH}$ usus merupakan tindakan kompetitif dengan patogen usus atau produksi zat dengan aktifitas neurotransmitter adalah beberapa mekanisme yang dikaitkan dengan strain probiotik yang dipilih untuk merangsang peristaltik usus. kedua, mengkonsumsi yogurt yang mengandung lactabcillus dapat mempersingkat waktu transit usus yang dapat membantu mempercepat gerakan peristaltik usus dan yang terakhir yogurt dapat mengencerkan Feses yang awalnya keras menjadi lunak tetapi tidak menyebabkan diare karna hanya melunakkan feses sehingga BAB menjadi lancar. Dari ketiga komponen aktif tersebut disimpulkan bahwa produk yang mengandung yogurt dengan polydextrose, secara signifikan mempersingkat waktu transit kolon setelah dua minggu dan dapat menjadi pilihan untuk mengatasi sembelit pada ibu hamil.

Hasil dari penelitian ini sejalan dengan penelitian yang telah dilakukan oleh Margro el al dengan judul 'Effect of Yogurt Containing Polydextrose, Lactobacillus Acidophilus NCFM And Bifidobacterium Lactis HN019 : A
Randomized, Double-Blind, Controlled Study In Chronic Constipation.", dengan mengkonsumsi yogurt sebayak $180 \mathrm{~m} / \mathrm{hari}$ pada kelompok eksperimen yang diberikan yogurt mengandung polydextrose dan pada kelompok control diberikan yogurt biasa selama 14 hari. Berdasarkan hasil statistic uji independen sample test dengan program SPSS dengan $p$ value $0,000<a(0,05)$. ini berarti ada pengaruh mengkonsumsi ygurt terhadap kejadian kosntipasi pada ibu hamil dan jika dari mean disimpulkan bahwa ada perbedaan konsumsi yogurt mengandung polydextrose dengan yogurt yang tidak mengandung polydextrose pada kejadian konstipasi pada ibu hamil.

Menurut pendapat peneliti berdasarkan hasil penelitian bahwa kontipasi yang terjadi pada ibu hamil frekuensi bab nya berbeda beda ibu dengan usia kehamilan $14-27$ minggu pada kelompok Yogurt Polydextrose sebanyak 7 orang ibu hamil (46.7\%) pada kelompok Yogurt sebanyak 8 orang ibu hamil $(53.3 \%)$ dan ibu hamil dengan usia kehamilan 28 - 41 minggu pada kelompok Yogurt Polydextrose sebayak 8 orang (53.3\%) sedangkan pada kelompok Yogurt sebanyak 7 (46.7\%). ibu hamil yang ada pada trimester kedua dan ketiga lebih sering mengalami konstipasi karena perubahan hormon dan seiring bertambahnya usia kehamilan, ukuran janin dapat menyebabkan obstruksi yang akan menghambat pengeluaran feses.

Bedasarkan hasil penelitian diatas didaptkan hasil uji $t$ independent didapat $p$ value $0,000, a(0,05)$ artinya $\mathrm{HO}$ ditolak dan Ha diterima, yang berarti ada pengaruh konsumsi yogurt terhdap kejadian konstipasi dan dilihat dari mean lebih besar yogurt yang mengandung polydextrose dari pada yang tidak mengandung polydextrose yang berarti ada perbedaan konsumsi yogurt yang mengandung polydextrose dengan yogurt terhadap kejadian onstipasi pada ibu hamil di BPM Fitri Hayati S.ST.

Hal ini sesuai dengan teori bahwa mengkonsumsi yogurt pada ibu hamil yang mengandung polydextrose lebih efektif dari pada yogurt yang tidak mengandung polydextrose pada ibu hamil yang mengalami kontipasi dan dapat disimpulkan mengkonsumsi yogurt menggandung polydextrose adalah adalah pilihan terbaik. Karna yogurt yang mengandung polydextrose mempunyai komponen aktif secara biologis. Pertama, mengkonsumsi yogurt dapat mengurangi ph diusus, penurunan $\mathrm{pH}$ usus merupakan tindakan kompetitif dengan patogen usus atau produksi zat dengan aktifitas neurotransmitter 
adalah beberapa mekanisme yang dikaitkan dengan strain probiotik yang dipilih untuk merangsang peristaltik usus. kedua, mengkonsumsi yogurt yang mengandung lactabcillus dapat mempersingkat waktu transit usus yang dapat membantu mempercepat gerakan peristaltik usus dan yang terakhir yogurt dapat mengencerkan Feses yang awalnya keras menjadi lunak tetapi tidak menyebabkan diare karna hanya melunakkan feses sehingga BAB menjadi lancar. Dari ketiga komponen aktif tersebut disimpulkan bahwa produk yang mengandung yogurt dengan polydextrose, secara signifikan mempersingkat waktu transit kolon setelah dua minggu dan dapat menjadi pilihan untuk mengatasi sembelit pada ibu hamil.

\section{KESIMPULAN}

Diketahui rata-rata frekuensi bab sebelum konsumsi yogurt yang mengandung polydextrose pada ibu hamil yang mengalami kontipasi di BPM Fitri Hayati S.ST Bandar Lampung Tahun 2019 Yaitu 2.33 dan sesudah konsumsi yogurt yang mengandung polydextrose pada ibu hamil yang mengalami kontipasi di BPM Fitri Hayati S.ST Bandar Lampung Tahun 2019 Yaitu 23.60. Lalu Diketahui rata-rata frekuensi bab sebelum konsumsi yogurt pada ibu hamil yang mengalami kontipasi di BPM Fitri Hayati S.ST Bandar Lampung Tahun 2019 Yaitu 2.27 dan sesudah konsumsi yogurt pada ibu hamil yang mengalami kontipasi di BPM Fitri Hayati S.ST Bandar Lampung Tahun 2019 Yaitu 19.20. Diketahui ada pengaruh Perbedaan konsumsi yogurt mengandung polydextrose dan yogurt terhadap kejadian konstipasi pada ibu hamil di BPM Fitri Hayati S.ST Bandar Lampung Tahun 2019. Hasil uji T didapat $p$ value $0,000<a(0,05)$.

Mengatasi konstipasi pada ibu hamil trimester ketiga, diantaranya : Konsumsi makanan berserat tiap hari, memperbanyak minum air putih, olahraga secara teratur, ajarkan cara efektivitas mengkonsumsi suplemen besi, anjurkan tidak minum obat pencahar. Rasional: untuk meningkatkan pemahaman klien tentang cara-cara mengatasi konstipasi. (Dwi Sulistyowati,2016).

Gula sederhana yang terkandung dalam ekstrak buah mangga diduga dapat dimanfaatkan oleh Bakteri Asam Laktat (BAL) untuk mendukung pertumbuhan dan meningkatkan aktivitasnya.(Harjiyanti,2013). Hasil penelitian Ahmad dalam Jannah menunjukkan bahwa semakin besar penambahan ekstrak buah belimbing pada yogurt drink dapat menurunkan total BAL dan $\mathrm{pH}$, serta meningkatkan keasaman. Yogurt drink dengan penambahan ekstrak buah belimbing cenderung agak disukai dengan citarasa cenderung asam. Penambahan ekstrak buah belimbing pada yogurt drink yang optimal dilihat dari total BAL, pH, keasaman, citarasa dan kesukaan terdapat pada perlakuan penambahan ekstrak buah belimbing 2\%.(Jannah,2014)

\section{SARAN}

Dapat dijadikan sebagai metode nonfarmakologi untuk mengatasi kontipasi yang terjadi pada ibu hamil sengan mengkonsumsi Yogurt Polydextrose yang sangat efektif untuk menyembuhkan sembelit.

Penelitian ini diharapkan Menambah informasi,wawasan dan pengetahuan kepada para ibu yang mengalami konstipasi dengan mengkonsumsi yogurt. Baik mengkonsumsi yogurt mengandung polydextrose lebih efektif dalam menangani konstipasi pada ibu hamil dan dapat juga mengkonsumsi yogurt biasa

\section{DAFTAR PUSTAKA}

AZIZA, Y. (2017). Pengaruh Yogurt Konjac Terhadap Kadar Glukosa Darah Pada Rattus norvegicus DIABETES (Doctoral dissertation, University of Muhammadiyah Malang).

Dwi Sulistyowati, Y. U. N. I. T. A., Winarsih Nur Ambarwati, S. K., \& Ns, E. T. N. (2016). Upaya Penanganan Konstipasi Pada Ibu Hamil Trimester III Di Puskesmas Grogol Sukoharjo (Doctoral dissertation, Universitas Muhammadiyah Surakarta).

Harjiyanti,el,al (2013). Total Asam, Viskositas Dan Kesukaan Pada Yoghurt Drink Dengan Sari Buah Mangga Sebagai Perisai Alami. JURNAL

Jannah et, al (2014). Total Bakteri Asam Laktat, Ph, Keasaman, Citarasa Dan Kesukaan Yoghurt Drink Dengan Penambahan Ekstrak Buah Belimbing. JURNAL

Klein, Susan \& Thompson Fiona. 2010. Panduan Lengkap Kebidanan. Yogyakarta : Nuha Medika

Kowalak, Jennifer Dan Huges.2010. Buku Saku Tanda Dan Gejala, Jakarta :EGC

Legowo, et, al. (2013). Pengaruh Penambahan Susu Skim Pada Proses Pembuatan Frozen Yogurt Yang Berbahan Dasar Whey Terhadap Total Asam, Ph Dan Jumlah Bakteri Asam Laktat. JURNAL

Mardalena, Ida. 2017. Dasar - Dasar IImu Gizi Dalam Keperawatan. Pustaka Baru Press. Yogyakarta. 
Margo et, al. Nutrition Journal. 2014. Effect Of Yogurt Containing Polydextrose, Lactobacillus Acidophilus NCFM And Bifidobacterium Lactis HN019 : A Randomized, Double-Blind, Controlled Study In Chronic Constipation. JOUNAL

Mu'alimah, M. (2019). Hubungan antara Asupan cairan dan konsumsi tablet $\mathrm{Fe}$ dengan kejadian Konstipasi Pada ibu hamil Trimester III Di Puskesmas Tanjung Anom Kabupaten Ngajuk tahun 2018 JHESTECH (Journal Of Health Educational Science And Technology), 2(1), 25-32.
Notoatmodjo, Soekidjo. 2014. Metodologi Penelitian Kesehatan, Rineka cipta Jakarta

Riza, N. (2017). Hubungan Konsumsi serat,air,tablet Fe dan aktivitas fisik dengan konstipasi pada ibu hamil di wilayah kerja Puskesmas Lubuk Buaya Kota Padang Tahun 2017 (Doctoral dissertation, Universitas Andalas).

WIDYASARI, S., \& Winarsih Nur Ambarwati, S. K. (2017). Upaya Penanganan Masalah Konstipasi Ibu Hamil Trimester III (Doctoral dissertation, Universitas Muhammadiyah Surakarta). 